\title{
Do gênero ao hipergênero, do hipergênero ao sistema de hipergenericidade: um estudo sobre o funcionamento discursivo do Facebook
}

\author{
From genre to hypergenre, from hypergenre to the hypergenre system: a study on \\ the discursive functioning on Facebook
}

Breno Rafael Martins Parreira Rodrigues Rezende*

\begin{abstract}
RESUMO: Neste artigo, que é fruto de uma pesquisa de mestrado ligada ao Programa de Pós-graduação em Estudos Linguísticos, da Universidade Federal de Uberlândia, apresentamos alguns resultados provenientes da análise discursiva que empreendemos em torno da rede social Facebook. Para tanto, valemo-nos do arcabouço teóricometodológico da Análise do Discurso de linha francesa, especialmente dos conceitos de gênero do discurso e hipergênero postulados por Dominique Maingueneau (2006, 2008b, 2010). Com efeito, o que pudemos demonstrar é que a rede social Facebook apresenta um comportamento discursivo distinto em relação a outros websites, implicando, assim, a formulação de novas categorias de análise. Em virtude disso, postulamos o conceito de sistema de hipergenericidade, que permitiu demonstrar que a pretensa "liberdade" enunciativa da Web, pelo menos no que diz respeito a essa rede social, não se aplica, uma vez que as identidades discursivas de suas páginas se inscrevem em um processo de legitimação que não é sem margens e que depende da relação que elas estabelecem com aquilo que nelas é posto a circular, especialmente sob a forma de compartilhamentos.
\end{abstract}

PALAVRAS-CHAVE: Análise do Discurso. Gênero do discurso. Hipergênero. Sistema de hipergenericidade.

\begin{abstract}
In this article, which is the result of a master's degree research linked to the Postgraduate Program in Linguistic Studies, at Federal University of Uberlândia, we present some results from the speech analysis that we carried out around the social network Facebook. For that, we use the theoreticalmethodological framework of French Discourse Analysis, especially the concepts of genre and hypergenre postulated by Dominique Maingueneau (2006, 2008b, 2010). In fact, what we have been able to demonstrate is that the social network Facebook has a distinct discursive behavior in relation to other websites, implying, thus, new categories of analyzes. As a result, we postulate the concept of a hypergenre system, which allowed us to demonstrate that the socalled enunciatively "freedom" of the Web, at least in relation to this social network, does not apply, since the discursive identity of its pages they are part of a process of legitimation that is not without limits and depends on the relation they establish with what is circulated in them, especially in the form of shares.
\end{abstract}

KEYWORDS: Discourse Analysis. Discourse Genre. Hypergenre. Hypergenre system.

\footnotetext{
* Mestre em Estudos Linguísticos pela Universidade Federal de Uberlândia. Atualmente é doutorando em Estudos Linguísticos pela mesma instituição.
} 


\section{Introdução}

As questões implicadas pela noção de gênero do discurso têm sido bastante investigadas por pesquisadores de várias áreas, inclusive por aqueles que se filiam à Análise do Discurso. É nesse sentido que Dominique Maingueneau (2006) afirma que muitas categorizações sobre tal noção foram produzidas.

No entanto, quando se trata de genericidade da Web, os estudos da área ainda são poucos, embora hoje se possa listar vários pesquisadores que se ocupam disso. No arcabouço teórico postulado por Maingueneau, por exemplo, verifica-se um interessante conjunto de conceitos, como o par hipergênero e cenografia, que permite que análises voltadas para a internet tenham uma entrada teórico-metodológica produtiva.

Entretanto, é possível ainda destacar um problema que se impõe quando a análise se volta para um objeto mais novo que a própria Web: a rede social, especialmente o Facebook. Isso porque, a questão da genericidade (ou hipergenericidade, como preferimos chamar) da Web se complexifica mais quando esbarra em coerções discursivas impostas pelo funcionamento de uma rede social, tendo em vista, por exemplo, as ferramentas de compartilhamento de que ela dispõe. Em busca de contribuir para a explicação desse tipo de fenômeno, empreendemos, neste artigo, a análise do Facebook tendo como mirante de partida a apresentação da noção de sistema de hipergenericidade (REZENDE, 2017) que postulamos.

A contribuição deste artigo decorre do fato de: i) se considerar um objeto de análise ainda pouco estudado - a rede social; ii) se demonstrar a produtividade de um conceito consagrado na agenda da Análise do Discurso francesa, a AD - o conceito de hipergênero; e iii) fazer andar a teoria ao se produzir um conceito que parece permitir avanços teóricos em torno da análise da rede social. 
É importante destacar que essa contribuição é fruto de uma pesquisa de mestrado realizada ${ }^{1}$ no Programa de Pós-graduação em Estudos Linguísticos da Universidade Federal de Uberlândia. Selecionamos três páginas públicas do Facebook para coletar os dados do corpus de análise que, por sua vez, será considerado para a apresentação do conceito de sistema de hipergenericidade, neste artigo, como um dos resultados dessa pesquisa.

Em relação ao tratamento desses dados, nos alinhamos a duas posições: a de Pêcheux ([1983] 1990) e a de Maingueneau (2008c). Segundo Maingueneau, o tratamento do corpus de análise parte de hipóteses fundamentadas na história (que podem ser confirmadas ou não) e em um conjunto de textos, considerando-se a relação inextrincável entre texto e contexto, entendidos pelo autor como discurso e condições de produção: uma posição radical que implica reconhecer que o texto é sempre analisado como prática discursiva e nunca como materialidade autônoma. Do ponto de vista pecheutiano, por sua vez, analisar implica reconhecer o movimento de alternância entre descrever e interpretar os dados como atitudes imbricadas. Sendo assim, assumir tais posições significa que analisar um corpus é ao mesmo tempo descrever sua materialidade histórica e explicar seu funcionamento. O pesquisador produz uma interpretação, que não é, em nenhuma medida, sem margens, e sim condicionada pela posição teórica de onde se põe a "ler os textos" (PÊCHEUX, 1990).

O artigo foi organizado em cinco seções: em Do gênero ao hipergênero, apresentamos o suporte teórico que fundamentou a análise das identidades discursivas de páginas inscritas no Facebook; em A construção de identidades discursivas no Facebook, demonstramos a constituição da identidade de uma página dessa rede social; em Do hipergênero ao sistema de hipergenericidade, apresentamos o conceito de sistema de hipergenericidade e o percurso teórico-investigativo que nos levou a

\footnotetext{
${ }^{1}$ Com apoio financeiro da Fundação de Amparo à Pesquisa do Estado de Minas Gerais (FAPEMIG).
} 
postulá-lo; nas Considerações finais demos destaque às questões mais relevantes da discussão deste artigo; encerramos com as Referências bibliográficas.

\section{Do gênero ao hipergênero}

De acordo com Maingueneau (2006), o gênero do discurso é definido como um dispositivo comunicacional sócio-historicamente constituído, o que implica que o estatuto comunicacional do gênero "prevê", em alguma medida, certas coerções enunciativas, como o estatuto dos parceiros, um determinado campo e tipo de discurso a que está ligado, entre outras.

No entanto, quando o autor trata da hipergenericidade da internet, ele afirma que as condições da comunicação que antes eram consideradas para a análise do gênero são transformadas, uma vez que a Web "não é apenas o lugar onde aparecem novas formas de genericidade: ela transforma as condições de comunicação, o que se considera gênero, e a própria noção de textualidade" (MAINGUENEAU, 2010, p. 132). Sendo assim, em relação à internet, Maingueneau coloca em xeque a produtividade da noção de gênero do discurso, que fora amplamente mobilizada para análises discursivas em um universo em que o oral e o impresso prevaleciam. Na Web, segundo o analista, o que se tem são hipergêneros.

Maingueneau introduz a categoria de hipergênero em Scénographie épistolaire et débat public, artigo publicado em obra organizada por J. Siess (La lettre entre réel et fiction) de 1998. Em 2008, o artigo de Maingueneau, traduzido por Décio Rocha, passa a integrar um dos capítulos de Cenas da enunciação (2008b), obra organizada por Sírio Possenti e Maria Cecília Souza-e-Silva e publicada pela editora Parábola, no Brasil. Nesse texto, ao analisar categorias como carta e diálogo, o analista verificou que elas se organizam em estruturas genéricas que apresentam restrições sócio-históricas fracas e que, além disso, mantêm relação íntima com a conversação. De acordo com o autor, tanto a carta como o diálogo podem veicular qualquer tipo de conteúdo e se prestam 
a situações de comunicação muito variadas, "explorando de maneiras diferentes esta forma básica da comunicação que é a troca de indivíduo a indivíduo" (MAINGUENEAU, 2008a, p. 122). Em função dessas características, a carta e o diálogo não são categorias tomadas por Maingueneau como gêneros, mas sim como hipergêneros.

Posteriormente, o conceito de hipergênero é retomado pelo autor em Discurso literário (2006) e parece receber "contornos" que possibilitam maior operacionalidade na análise de textos. Nessa obra, Maingueneau afirma que os hipergêneros são estruturas que permitem "formatar" o texto, isto é, são estruturas que permitem organizar diferentes encenações de fala que podem ser encontradas em diferentes épocas e lugares. Nas palavras do autor:

[O hipergênero] trata-se de categorizações como "diálogo", "carta", "ensaio", "diário", etc. que permitem "formatar" o texto. Não se trata, diferentemente do gênero do discurso, de um dispositivo de comunicação historicamente definido, mas um modo de organização com fracas coerções que encontramos nos mais diversos lugares e épocas e no âmbito do qual podem desenvolver-se as mais variadas encenações da fala (MAINGUENEAU, 2006, p. 244).

É possível, pois, afirmar que, para Maingueneau, o hipergênero não pode ser tomado como um dispositivo de comunicação sócio-historicamente constituído, como é o gênero do discurso, mas como um modo de organização da fala que sofre coerções enunciativas mais fracas. Isso porque quando a enunciação se origina de um dispositivo sócio-historicamente constituído é (quase) possível entrever como serão preenchidos os papéis dos interlocutores na enunciação em curso. No entanto, de acordo com o autor, quando um hipergênero é mobilizado na enunciação, o que está em jogo é como o que é dito é semantizado, ou seja, o modo de dizer e de formatar os conteúdos que são enunciados. 
Segundo Maingueneau, ao longo da história, alguns hipergêneros podem ser tomados como bons exemplares dessa categoria. O diálogo, por exemplo, durante o século XVI, foi mobilizado como forma privilegiada do debate de ideias; a carta, por outro lado, assumiu esse lugar ao longo do século XVII. Não obstante, o que o autor verificou é que ambas as categorias permitem "formatar" os mais diversificados conteúdos em um texto. No entanto, o hipergênero, ainda de acordo com o analista, não pode ser tomado como mero molde para conteúdos independentes dele; a encenação da fala do enunciador instaura o quadro de comunicação por meio do qual a enunciação é semantizada.

Em Hipergênero, gênero e internet (2010), Maingueneau assume que os websites podem ser analisados segundo o conceito de hipergênero. Para o autor, como já esclarecido, a internet opera mudanças significativas na maneira como os gêneros passam a ser compreendidos, uma vez que as condições clássicas da noção de gênero são diferentes na internet.

Segundo Maingueneau, dois movimentos convergentes podem ser observados a partir das coerções comunicacionais que a Web impõe. O primeiro deles diz respeito ao fato de que as coerções genéricas, com o advento da internet, estão se tornando mais fracas. Tal afirmação, para o autor, pode ser explicada com base na noção de que todas as unidades comunicacionais da Web são da mesma ordem, são websites submetidos “a uma larga escala de restrições técnicas” (MAINGUENEAU, 2010, p. 133, grifo nosso). O segundo movimento diz respeito à hierarquia da cena de enunciação que abarca cena englobante, cena genérica e cenografia. $\mathrm{Na}$ Web, a cenografia, em detrimento das outras cenas, passa a ter papel central, uma vez que o que se está em voga é encenar a comunicação de acordo com as estratégias de seus produtores.

Em relação às três instâncias da cena de enunciação, de acordo com Maingueneau (2008b), a cena englobante diz respeito ao tipo de discurso (religioso, literário, publicitário, etc.); a cena genérica refere-se ao gênero do discurso ao qual o 
enunciado pertence (propaganda, notícia, carta); a cenografia, por sua vez, não é imposta pelo tipo, e tampouco pelo gênero do discurso; mas é construída no e pelo próprio discurso.

Ainda de acordo com o autor, o leitor, ao deparar-se com uma cenografia, estará sob "ameaça" de "uma armadilha". Isso porque a cenografia imposta pelo discurso "dissimula" uma cena de fala da qual o texto se origina. Um exemplo do próprio analista são os libelos jansenistas que circularam na França do século XVI sob a cenografia de "carta". No entanto, para ele, qualquer que seja a cenografia, ela não implica a alteração da cena genérica: a função social acusatória do libelo foi mantida para o leitor "ameaçado" pela "armadilha".

Segundo afirma, a cenografia é construída para validar o discurso, de modo que sua escolha não é indiferente. Em um movimento convergente, a cenografia, que é imposta desde o início pelo discurso, é legitimada ou não pela própria enunciação: “é necessário que [o discurso] faça seus leitores aceitarem o lugar que ele pretende lhes atribuir nessa cenografia e, de modo mais amplo, no universo de sentido do qual ele participa", de modo que a cenografia vai legitimando e sendo legitimada pelo discurso (MAINGUENEAU, 2008b, p. 117).

Em relação a sua hipótese, de que os websites podem ser analisados segundo o conceito de hipergênero, Maingueneau (2010), para sustentá-la, analisa dois blogs, em que verifica que a estrutura arquitetônica e o suporte físico de ambos são basicamente os mesmos (os recursos gráficos de formatação dos blogs são idênticos - é possível alterar apenas os esquemas de cores de cada página, as fontes dos textos publicados, o background, etc.), uma vez que eles dependem das mesmas ferramentas gráficas impostas pelos desenvolvedores ${ }^{2}$ que os hospedam na Web. Essa restrição técnica que a internet impõe é tomada pelo analista como um forte indício da hipergenericidade

\footnotetext{
${ }^{2}$ No Brasil, podemos criar blogs a partir da hospedagem do Uol e do Blogspot (administrado pelo Google), por exemplo.
} 
de cada site, já que as restrições técnicas impostas pela internet "obrigam" que os enunciadores construam cenografias para instituírem a identidade discursiva de suas páginas. É nesse sentido que as noções de hipergênero e cenografia, nesse processo de teorização estabelecido por Maingueneau, devem ser tomadas de maneira inextrincável, uma vez que, do ponto de vista discursivo, o conceito de hipergênero, por si só, não é suficiente para descrever/explicar processos relevantes envolvidos na discursivisação. É o conceito de cenografia que possibilita a abordagem dos processos enunciativos que configuram as identidades discursivas. Assim, considerar apenas a noção de hipergênero implica reduzir a noção de texto/discurso à "estrutura", já que, no quadro proposto pelo autor, é no nível da cenografia que se encenam as inscrições dos enunciadores. Desse modo, para Maingueneau, a escolha da cenografia é sempre significativa e implica transformações sociais. Definir a cenografia permite ao locutor impor um quadro de comunicação, colocando em voga o sentido de sua própria atividade semiótica, a imagem dos parceiros, a inter-relação entre eles, etc. Para o autor, a cenografia, nesse sentido, é responsável por criar uma identidade discursiva para os sites, visto que eles não podem diferenciar-se entre si pela estrutura formal dos textos que neles são publicados.

O conceito de hipergênero formulado por Maingueneau, associado a seu conceito de cenografia, possibilita, nesse sentido, avanços para o quadro de análise de discurso que mobilizamos nesta pesquisa: através dele é possível verificar os sentidos que emergem da enunciação que se origina de textos que sofrem restrições sóciohistóricas fracas. O conceito de hipergênero, poderia, ao menos a princípio, "dar conta" dos dados provenientes da rede social Facebook, uma vez que nessa rede é também possível constatar a mobilização de diferentes cenografias na construção de identidades discursivas de diversas páginas. Entretanto, mais especificamente em relação a essa rede social, apenas a hipergenericidade da Web não é suficiente para 
explicar o sistema de relações semânticas implicado pelo funcionamento discursivo do Facebook, como buscaremos demonstrar.

\section{A construção de identidades discursivas no Facebook}

Ao analisar diferentes blogs, Maingueneau (2010) observa que cada site tem em si um estatuto comunicacional bem definido: o blog de uma prostituta, por exemplo, apesar de construir em/por seu discurso uma encenação de diário pessoal, tem por objetivo expor o serviço que nele se anuncia; o blog de um time de futebol, por outro lado, tem por objetivo expor os dados técnicos, notícias e etc. que envolvem o time para seus eventuais torcedores. Como já dito na seção anterior, nessa análise, a conclusão a que o analista chega é a de que, embora a arquitetura de cada site seja a mesma, a identidade de cada um deles é criada segundo a cenografia que eles constroem para tentar validar seus discursos, de acordo com seus objetivos comunicacionais.

Algumas características do hipergênero que são postuladas por Maingueneau (2010), a partir da análise de blogs, podem também ser verificadas nas enunciações que são construídas no Facebook. A unidade entre todas as páginas inscritas no Facebook é dada segundo as restrições técnicas - comuns a todas as unidades comunicacionais da $\mathrm{Web}^{3}$ - que são impostas aos usuários para que eles possam proceder às suas publicações: os elementos gráficos e as ferramentas disponíveis para a produção de texto são as mesmas de página para página. Nesse sentido, tais restrições técnicas implicam fortemente a construção de cenografias no processo de instituição identitária das páginas inscritas nessa rede social.

Sendo assim, como ocorre com outros websites, as cenografias que são construídas nas páginas do Facebook variam, assim como variam as identidades

\footnotetext{
${ }^{3}$ Aqui entendidas como qualquer dado da Web, como uma página, uma notícia, uma imagem, etc.
} 
discursivas inscritas nessa rede social. Em uma das páginas que selecionamos para a coleta de dados, a Quebrando o tabu, é possível verificar que as cenografias construídas são de "fórum de discussão", diferentemente do que ocorre em uma página de empresa ou de um jornal, que tenta construir para si uma identidade "mais neutra", a fim de divulgar a um público amplo sua marca, como é o caso do Pão de açúcar e da Folha de S. Paulo . Na página, Quebrando o tabu, as publicações veiculam opiniões mais "progressistas" em torno de diferentes assuntos polêmicos que circulam no mundo,

mas sobretudo no Brasil. É uma página que conta com mais de quatro milhões de “curtidas5" (dado verificado no domínio https://goo.gl/TWZPjb em 18/07/ 2016).

O nome Quebrando o tabu foi inspirado em um documentário homônimo de 2011, dirigido por Fernando Grostein Andrade, sobre o debate das drogas e da violência no Brasil ${ }^{6}$. No entanto, a página, apesar da nítida referência ao filme, faz circular muitos outros temas, que dividem a opinião daqueles que acessam suas publicações no Facebook. Em geral, os administradores da página introduzem uma notícia compartilhada, ou uma imagem, ou uma charge, entre outros, por meio de dizeres que atestam o posicionamento mais "progressista" que observamos emergir do discurso de Quebrando o tabu. Vejamos um exemplo7:

\footnotetext{
${ }^{4}$ Páginas que também foram analisadas na dissertação de mestrado que deu origem a este artigo.

${ }^{5} \mathrm{O}$ número de "curtidas" de uma página como as que selecionamos para a coleta de dados é relativo ao número de usuários do Facebook que segue cada uma delas.

${ }^{6} \mathrm{Cf}$. http://www.quebrandootabu.com.br/sobre/projeto. Acesso em: 18 jul.2016.

${ }^{7}$ https://goo.gl/hXktJe. Acesso em: 18 jul.2016.
} 
1)

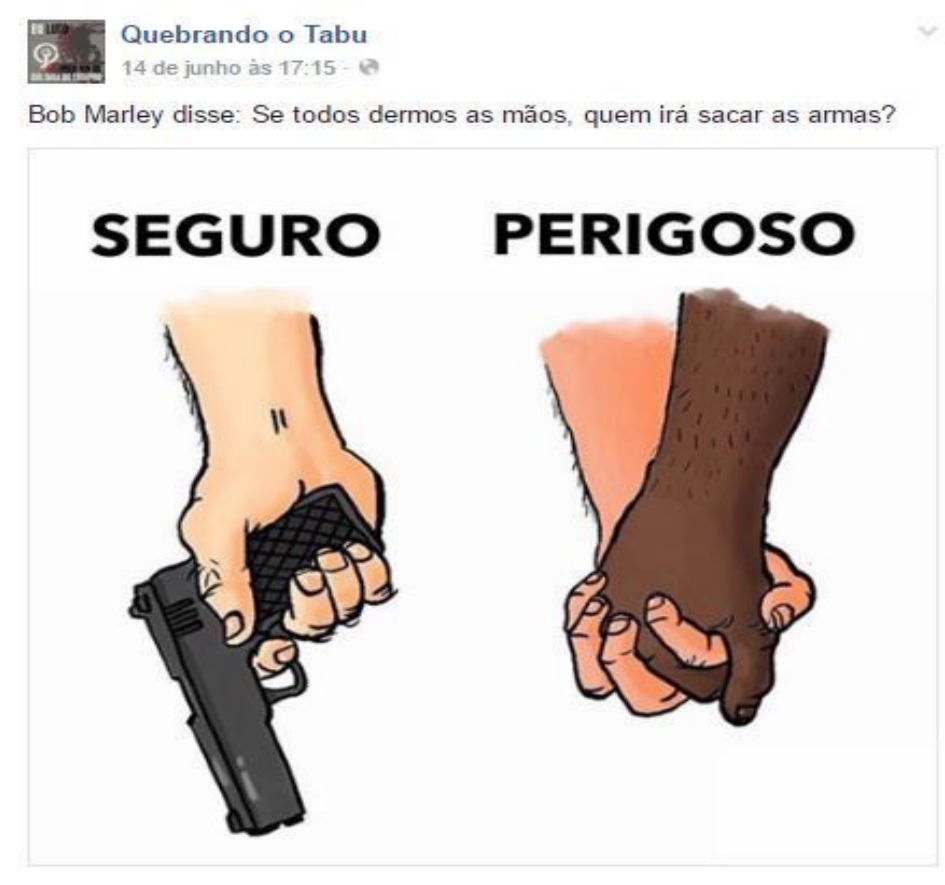

Em (1), observamos uma charge veiculada pela página, em que se contrastam uma mão segurando uma arma de fogo e outras duas mãos "dadas" com traços masculinos (como o tamanho dos membros, os braços mais grossos e com pelos, etc.), introduzida pelos dizeres: “Bob Marley disse: Se todos dermos as mãos, quem irá sacar as armas?". A charge em questão parece fazer alusão ao atentado do dia 12/06/2016 que ocorreu em uma boate LGBTQ ${ }^{+}$nos Estados Unidos, em que 49 homossexuais foram assassinados e muitos outros foram gravemente feridos. Tal ocorrido ainda levantou a discussão sobre a política de armas no mundo, sobretudo pelo fato de os EUA não proibirem o armamento de civis em sua constituição, além de fazer referência ao racismo pela cor negra de uma das mãos "dadas” e pela referência a Bob Marley, artista que também ficou conhecido por lutar em prol da igualdade entre as diferentes raças.

Em geral, os temas que circulam na página de Quebrando o tabu, como já dito, são polêmicos e incitam o debate entre os diferentes enunciadores que a acessam, o 
que, em primeira análise, é indicado também pelo próprio nome da página, em que se verifica a necessidade de se falar sobre tabus, ou seja, sobre assuntos socialmente evitados. A página é "rotulada" no Facebook como uma página midiática, de entretenimento e de notícias; entretanto, o posicionamento que emerge de suas publicações parece construir nesses textos uma cenografia de "fórum de discussão" que "promove" o debate sobre os diferentes temas que as publicações colocam em pauta. Sendo assim, a cenografia de "fórum de discussão", analisada em (1), é construída pela inscrição da página em um posicionamento específico, que classificamos como "mais progressista".

Com base nessa breve análise, é possível considerar que as publicações do Facebook são casos exemplares de hipergênero, uma vez que permitem semantizar diferentes tipos de conteúdos (no caso apresentado, assuntos polêmicos que são colocados em pauta, a partir de uma cenografia de "fórum de discussão", construída segundo a inscrição da página em um posicionamento específico), além de estarem, em alguma medida, submetidas ao aspecto técnico imposto pela Web e à construção de cenografias que buscam validar as identidades discursivas que circulam e que se relacionam nessa rede social (características atestadas nas análises de Maingueneau (2006; 2008b; 2010), que foram mobilizadas na construção do conceito de hipergênero).

No entanto, o que também observamos é que o conceito de hipergênero se mostra restrito para apreender a natureza discursiva dessa rede social, uma vez que o Facebook, por meio da ferramenta de compartilhar, é capaz de relacionar diferentes unidades comunicacionais da internet, como dados de outros websites, fotos e vídeos.

Sendo assim, assumir que a hipergenericidade que se verifica na construção das páginas dessa rede social é suficiente para descrever a natureza do Facebook é problemático. Isso porque, nessa rede social, há um outro aspecto de seu funcionamento, relativo ao fato de que ali tudo (ou quase tudo) pode ser compartilhado e posto a circular. Nesse sentido, não se trata apenas de verificar a 
hipergenericidade de tais páginas, mas também de verificar a possibilidade de se considerar a existência de um sistema que é capaz de englobar toda essa hipergericidade da Web, como se o Facebook pudesse ser tomado como uma "janela do mundo", através da qual "tudo" pode ser posto em relação.

Na próxima seção deste artigo, ampliaremos essa reflexão a partir da postulação do conceito de sistema de hipergenericidade, conceito que se mostrou produtivo para explorar a natureza do funcionamento discursivo dessa rede social.

\section{Do hipergênero ao sistema de hipergenericidade}

Conforme já dito, a ferramenta de "compartilhar" do Facebook parece indiciar que essa rede social tem uma natureza diferente, quando comparada a outros websites, como aqueles analisados por Maingueneau. Por meio dela, é possível que cada página coloque a circular, em seu interior, um número irrestrito de unidades comunicacionais que circulam em outros domínios da Web. Entretanto, o compartilhamento parece não ser sem margens: cada página compartilha aquilo que lhe é "legítimo" compartilhar, a depender da relação construída entre sua própria identidade discursiva (atestada pelas cenografias que se constroem em diferentes publicações) e o campo semântico que engloba as unidades compartilhadas.

Conforme demonstramos em trabalho anterior (cf. REZENDE, 2016), a ferramenta de compartilhar do Facebook não funciona apenas como um recurso de software. No nível discursivo, ela cumpre a função de, entre outras coisas, instaurar um quadro de comunicação efetivo. Desse modo, essa ferramenta do Facebook, conforme hipótese que pudemos sustentar, possibilita que tudo o que esteja no domínio da Web possa ser posto em relação no interior dessa rede social, desde que legitimado pela identidade discursiva que cada página busca instituir.

Na seção anterior, buscamos sustentar que a página selecionada para a análise tem uma identidade discursiva atribuída a si, que decorre das cenografias 
mobilizadas/construídas na enunciação. Conforme o conceito de hipergênero (MAINGUENEAU, 2006; 2008b; 2010), é justamente a identidade discursiva, atestada pelo aspecto cenográfico da Web, que permite ao usuário ${ }^{8}$ da internet semantizar aquilo que é dito.

No entanto, parece-nos que o compartilhamento no Facebook instaura um princípio de sistematicidade entre a página que compartilha e o dado que nela é compartilhado, tendo como elemento de coesão a relação estabelecida entre o campo semântico da unidade compartilhada e a identidade discursiva da página que compartilha. Tal sistematicidade deve ser entendida de forma ampla, de modo a contemplar tanto a delimitação dos temas abordados pelas páginas, quanto aspectos relacionados à convergência das funções sociais dos gêneros do discurso postos em relação por meio de compartilhamentos, como o alinhamento de posicionamentos entre páginas compartilhadas.

Com efeito, o compartilhamento parece fazer imperar um funcionamento singular para aquilo que é colocado a circular no interior do Facebook: não se trata apenas do modo de semantização daquilo que é dito; tal funcionamento faz convergir para o interior dessa rede social um número indiscriminado de páginas da Web que são colocadas em relação, em função da identidade discursiva da página do Facebook em questão.

A página de Quebrando o tabu, como demonstrado anteriormente, põe a circular no interior do Facebook cenografias que encenam uma espécie de "fórum de discussão", em virtude das temáticas que na página são abordadas e do posicionamento dessa página em relação aos temas que ela coloca em pauta. Nesse sentido, os compartilhamentos dela, em geral, são orientados pela relação dessa cenografia de

\footnotetext{
${ }^{8}$ Do ponto de vista terminológico, mobilizar o termo "usuário" não compromete as delimitações teóricas assumidas. Indica, por outro lado, a alternância que se assume entre a internet como ferramenta e a internet como dispositivo discursivo-comunicacional.
} 
"fórum de discussão" com assuntos polêmicos, que podem circular em outras páginas dessa mesma rede social ou em outros domínios da Web, como no exemplo a seguir?

2)

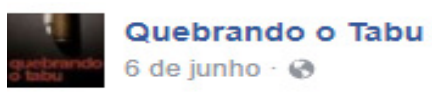

"Não foi fácil me expor e conviver com as marcas dessa violência. Não existe aqui a Luiza. Existem mulheres." @
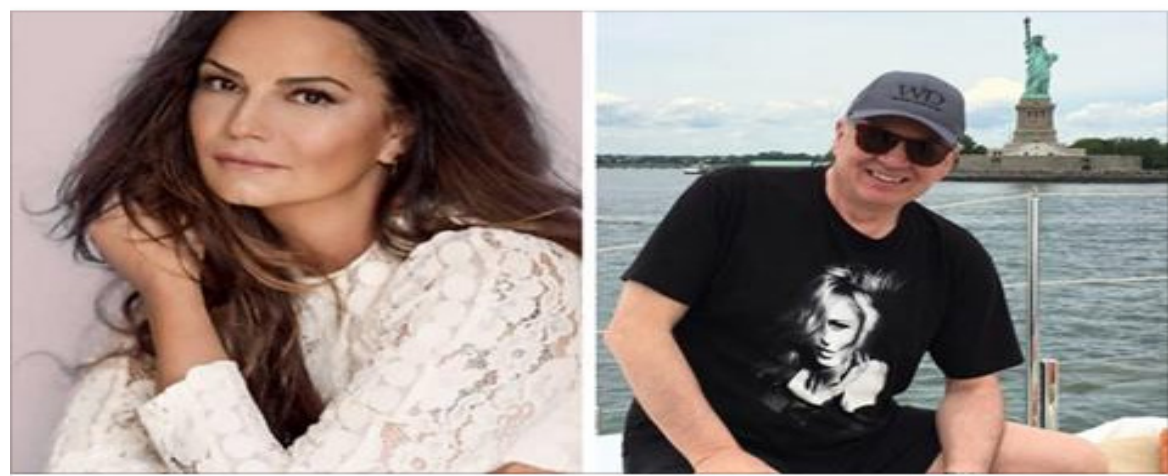

'Este dia não é só meu': Luiza Brunet dedica condenação de Lírio Parisoto às mulheres

"Não foi fácil me expor e conviver com as marcas dessa violência. Não existe aqui a Luiza. Existem mulheres."

HUFFPOSTBRASIL.COM

Em (2), observamos o compartilhamento, pelo Facebook de Quebrando o tabu, da notícia do site huffpostbrasil.com sobre a condenação do empresário Lírio Parisoto pela agressão cometida contra a modelo e atriz Luiza Brunet, sua esposa até então. Ao observarmos o que fora compartilhado, é possível verificar que a notícia no Facebook é introduzida por um trecho do que a atriz postou na internet sobre a condenação de Parisoto, dado que também consta na publicação de HuffPost. Ao fazê-lo, Quebrando o tabu coloca em pauta não apenas o fato noticiado, mas também o problema da violência contra as mulheres, o que parece ocorrer também na publicação de HuffPost. Vejamos:

${ }^{9}$ https://goo.gl/FfhH9m. Acesso em: 27 jun.2017. 
3)

EDITION

(8)

\section{IHUFFPOST}

NOTICIAS

VOZES

MULHERES

LGBT

COMPORTAMENTO

VIRAL

ENTRETENIMENTO

ETC

\section{MULHERES}

\section{'Este dia não é só meu': Luiza Brunet dedica condenação de Lírio Parisoto às mulheres}

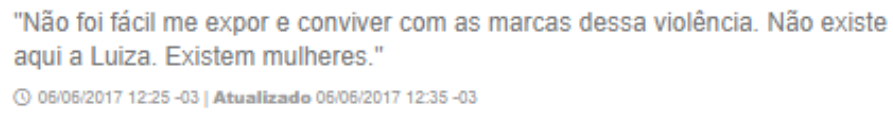

"Não foi fácil me expor e conviver com as marcas dessa violência. Não existe aqui a Luiza. Existem mulheres."

(1) 06:06:2017 12:25-03| Atualizado 06:106/2017 12:35-03

\section{\begin{tabular}{l|l|l|l|}
$\mathbf{f}$ & $\because$ & $\mathbb{G}$ & in
\end{tabular}}

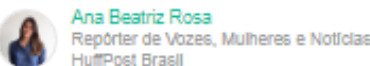

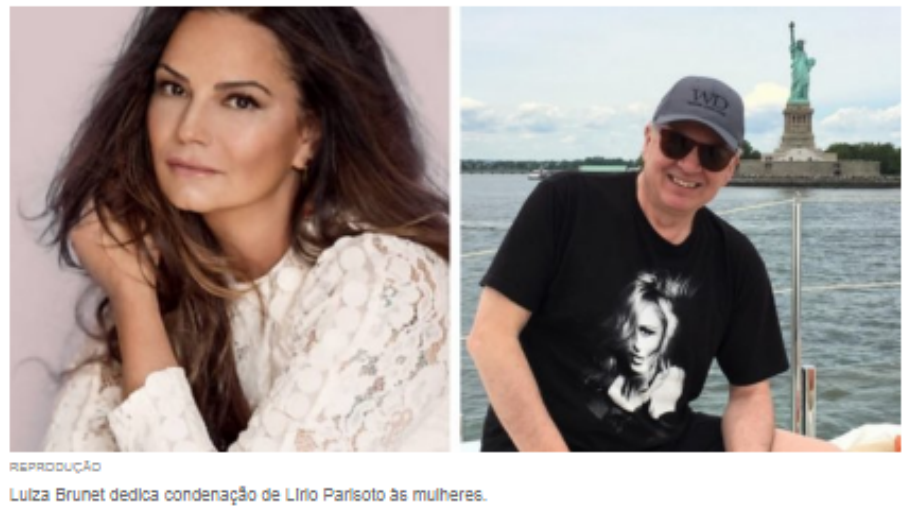

Na última terça-feira (05), uma sentença do Tribunal de Justiça São Paulo decidiu que o empresário Lírio Parisotto foi condenado a um ano de prisão por ter agredido Luiza Rnunet

\author{
BOMBANDO \\ Uma mulher começou a cantar \\ 'Evidências' no metrô de Săo Paulo e năo \\ teve um que resistiu à cantoria \\ 21 destinos nacionais que náo parecem \\ estar no Brasil \\ TV americana elege as nacionalidades \\ mais legais do mundo. E adivinha quem \\ está em $1^{\circ}$ lugar? \\ Masculinidade nua e crua: 100 homens \\ expóem pênis em fotos para explorar \\ virilidade \\ 12 filmes com cenas reais de sexo (que \\ năo săo pornôs) \\ Jovens negras amontoadas em camas de \\ cimento: 0 sistema prisional feminino no \\ País
}

Em (3), tem-se a captura de tela da notícia postada por HuffPost. É importante observar que esse site de origem norte-americana, que tem edições em vários países, parece seguir uma orientação "mais progressista" em relação aos assuntos que aborda (geralmente assuntos que engendram maior polemicidade), assim como Quebrando o tabu no Facebook. Tal consideração pode, entre outras coisas, ser analisada segundo o próprio termo "huffpost", que pode ser tomado como referência ao nome de uma de suas fundadoras, Arianna Huffington ${ }^{10}$, mas também como um neologismo que significa "postagem irritada", o que permite supor um posicionamento específico, 
contestador, frente aos temas que esse site aborda. Isso porque, "huff" significa, em português, "irritação" quando não antecedido pela marca de infinitivo "to"11 da língua inglesa.

Assim como a página de Quebrando o tabu, HuffPost parece colocar em pauta temas ligados à defesa dos direitos das minorias, o que pode ser atestado pelas "seções" do site que aparecem na captura de tela em (3), como "LGBT", "mulheres", etc. É justamente esse alinhamento dos posicionamentos das duas páginas que parece legitimar o fato de a notícia de HuffPost ter sido compartilhada por Quebrando o tabu. Assim sendo, o compartilhamento de Quebrando o tabu, em geral, é orientado pela posição "mais progressista", em relação às temáticas abordadas.

Esse dado pode nos permitir supor que o aspecto do campo semântico que se apresenta como organizador do compartilhamento de Quebrando o tabu no Facebook está intimamente relacionado à convergência do posicionamento das páginas postas em relação. Ou seja, um posicionamento que legitima temas que podem ser tomados como mais polêmicos, em função de uma certa necessidade de se combater preconceitos e defender minorias, o que se observa, pelo menos, nos exemplos (1), (2) e (3) que foram apresentados.

Como deve ter sido possível observar, a partir da análise do sistema de compartilhamento da página analisada, a identidade discursiva dela, em função da mobilização de certo aspecto de um campo semântico - o posicionamento frente ao tema abordado -, legitima aquilo que pode ser compartilhado e posto em relação no interior do Facebook. Trata-se, na verdade, da instauração de um sistema em que tudo converge para a manutenção da identidade da página, ao qual nos referiremos como sistema de hipergenericidade, na medida em que o que é posto em relação são, em última instância, páginas da Web, consideradas por Maingueneau (2010) como hipergêneros.

\footnotetext{
11 "To huff", em português, significa "xingar".
} 
Vale ressaltar que a mobilização do conceito de sistema é feita por analogia à concepção de sistema formulada por Ferdinand de Saussure ([1916] 2012), cujos elementos ganham identidade a partir das relações que estabelecem com os demais elementos desse sistema. Por implicar a noção de relação, o conceito de sistema parece produtivo para se considerar os processos relacionais em que as páginas se inscrevem ao compartilharem dados de outros domínios da Web, na busca por uma manutenção identitária.

Correlativamente, a relação entre as identidades das páginas do Facebook com as unidades que nelas são compartilhadas submete-se a um funcionamento discursivo, que legitima o que se pode ou não compartilhar, aos moldes de um sistema de restrições semânticas, tal qual é postulado por Maingueneau (2008c) em Gênese dos discursos. Segundo o autor, o sistema de restrições semânticas está ligado ao funcionamento da competência discursiva de sujeitos inscritos em um dado posicionamento. Sendo assim, esse sistema produz uma "filtragem" por meio da qual o discurso legitima ou não aquilo que pode ser enunciado a partir de um posicionamento. Com base nesse aspecto, também é possível aproximar o conceito de sistema de restrições semânticas do conceito de sistema de hipergenericidade: em ambos os casos, o que está em jogo são as regularidades de um funcionamento discursivo que conflui para a manutenção de um dado/a posicionamento/identidade discursivo/a.

Tendo em vista a noção de relação como caminho que permite que o compartilhamento funcione como um operador das identidades discursivas de cada página do Facebook, observamos que aquilo que é compartilhado na página de Quebrando o tabu está ligado à orientação do posicionamento que emerge das publicações dessa página, legitimando o compartilhamento daquilo que pode ser alinhado ao posicionamento em que ela se inscreve. 
Mas se há um sistema de hipergenericidade, em que medida a recorrente afirmação de que na internet não há fronteiras estabelecidas se sustenta? Tal afirmação apresenta-se produtiva apenas para a análise do mídium Web, que não se confunde com sistema de hipergenericidade.

Tributário da noção de midiologia de Regis Debray (1993), o conceito de mídium de Maingueneau corresponde, em última medida, às mediações da linguagem pelas quais uma ideia é revestida de força material. Em Análise de textos da comunicação, Maingueneau (2008a) afirma que o mídium não é meramente um "acessório" para a enunciação, mas uma dimensão que deve ser considerada no dispositivo comunicacional que ela engendra, integrada, entre outras coisas, ao gênero e ao suporte físico do enunciado "logo de saída".

Tendo em vista esse aspecto do mídium, Zati (2016), em sua dissertação de mestrado, postula que, na comunidade de produtores de fanfictions ${ }^{12}$, há certos enunciadores - os chamados ripadores - que se prestam a vituperar os textos de ficwriters (escritores de fanfictions) que consideram mal escritos. Para tanto, ainda de acordo com a analista, esses ripadores mobilizam um registro linguístico verbalmente violento e justificam essa prática afirmando que a internet é um espaço público e aberto, em que se pode enunciar o que quiser, da maneira como quiser. Esse "efeito de liberdade" instaurado no/pelo funcionamento enunciativo provém, segundo tese defendida pela autora, da internet analisada do ponto de vista do mídium.

No entanto, no que tange ao compartilhamento do Facebook, com base na análise apresentada, existem restrições semânticas. É nesse sentido, pois, que as duas dimensões, mídium e sistema de hipergenericidade, não se confundem. O que ocorre é que, do ponto de vista metodológico, há possibilidade de se abordar as produções discursivas na internet a partir, pelo menos, de dois níveis de análise, a saber, o do

\footnotetext{
12 Uma comunidade de escritores de textos ficcionais, geralmente publicados na internet, baseados no universo literário de obras já consagradas pelo mercado ou pelo campo da Literatura.
} 
mídium e o do sistema de hipergenericidade. Isto porque, na verdade, do ponto de vista de eventos enunciativos concretos, há dois movimentos que, paradoxalmente, se alimentam: o movimento de conexão em rede ad infinitum do mídium Web, que alimenta a ilusão de que a internet, incluindo nela a ferramenta de compartilhamento do Facebook, é livre de restrições, e o movimento do sistema de hipergenericidade, que faz convergir, por meio dessa ferramenta, apenas unidades da Web que confluem para a manutenção das identidades discursivas.

Nesse sentido, o termo "rede" não nos pareceu proveitoso para categorizar o funcionamento da rede social Facebook, uma vez que o conceito de rede evoca uma condição de "dispersão" (ou seja, a ideia de que os dados podem ser dispersos e mobilizados sem uma orientação específica), que é, na verdade, típica do efeito de liberdade implicado pelo funcionamento do mídium. Diferentemente, classificar a rede social como um "sistema" pode permitir melhor analisá-la, uma vez que, como buscamos demonstrar por meio das análises, os dados que circulam no Facebook são orientados pela relação que a identidade discursiva de cada página estabelece com o que nelas é posto a circular, especialmente sob a forma de compartilhamento. Nesse sentido, nada está disperso. Ao contrário, há uma orientação que permite atestar a identidade discursiva de cada página, especialmente observando-se o que nelas é compartilhado, na medida em que as unidades compartilhadas no Facebook dependem sempre da relação que uma página estabelece com as outras, em função de certo modo de mobilização de aspectos de um campo semântico. Dessa perspectiva, a propagada liberdade de se "expressar" livremente na rede social, em termos de linguagem, não procede, uma vez que a enunciação submete-se às regras de um funcionamento discursivo. 


\section{Considerações finais}

Ao dar início a esta pesquisa, assumíamos como hipótese que o Facebook poderia, à maneira dos websites analisados por Maingueneau (2010), ser categorizado como um hipergênero. No entanto, a natureza desse objeto se mostrou, ao longo da análise que íamos empreendendo, mais complexa, o que impôs que levássemos em conta outros aspectos de seu funcionamento.

Como foi possível perceber por meio da análise, o conceito de hipergênero postulado por Maingueneau permitiu verificar como são construídas as identidades discursivas das páginas inscritas no Facebook, processo que se mostrou atrelado à construção de cenografias que permitem, a quem enuncia nessa rede social, impor um modo de semantização daquilo que é dito.

No entanto, analisar como as identidades discursivas são construídas no Facebook não se mostrou suficiente para que pudéssemos descrever e explicar os processos do complexo funcionamento discursivo dessa rede social, sobretudo em função do efeito implicado pelo uso da ferramenta de compartilhar (que funciona como um meio pelo qual diferentes unidades da Web integram a semântica de cada página), o que nos impôs a necessidade de investir em uma extensão do conceito de hipergênero (MAINGUENEAU, 2006, 2008b, 2010). A partir de tal extensão, foi possível verificar, por meio da análise dos compartilhamentos que são produzidos, o funcionamento de um sistema que conflui para a manutenção das identidades discursivas das páginas do Facebook. As regras desse funcionamento, como demonstramos, estão sempre atreladas a certo modo de mobilização de aspectos de um dado campo semântico que permite, a quem enuncia nessa rede social, relacionar as unidades compartilhadas à identidade discursiva que se constrói em cada uma de suas páginas. Com base, então, na observação desse funcionamento, postulamos o conceito de sistema de hipergenericidade, que se mostrou produtivo para a 
abordagem de nosso corpus de análise que, em se tratando de rede social, é tão novo e produtivo quanto o mirante discursivo que se visa postular.

Assim sendo, os resultados alcançados nesta pesquisa possibilitaram, a nosso ver, avanços, uma vez que a análise da rede social Facebook permitiu que ampliássemos a noção de hipergênero, considerando a existência de sistemas de hipergenericidade. Nesse sentido, consideramos que a Web, especialmente a rede social, constitui-se em um espaço de coleta de dados relevante a ser investigado pelas pesquisas em Análise do Discurso, na medida em que pode possibilitar ampliação e/ou refinamento de seu quadro teórico.

A respeito do dados de uma pesquisa, Possenti (2009) afirma que há uma distinção que os pesquisadores devem considerar na mobilização desses dados. De acordo com o autor, dois tipos de dado são proeminentes no trabalho de pesquisa em AD: o "dado dado" e o "dado dado". Possenti esclarece que o primeiro tipo de dado é tomado como evidência de um pressuposto teórico, enquanto que o segundo tipo é aquele tomado como dado a ser testado, que evoca problemas e que faz com que uma teoria se desenvolva. Dessa perspectiva, considerando a análise que fizemos em torno da rede social Facebook, é possível afirmar que o corpus analisado seja constituído tanto de "dados dados", por meio dos quais postulados de Dominique Maingueneau foram corroborados, quanto de "dados dados", por meio dos quais pudemos demonstrar a produtividade de um novo conceito para o quadro da $A D$ - o de sistema de hipergenericidade -, possibilitando, pois, avançar a teoria.

Não obstante, para futuras pesquisas, seria importante averiguar se o conceito de sistema de hipergenericidade que postulamos é produtivo também para a análise de outras redes sociais que, empiricamente, englobam um grande número de páginas e de links compartilhados. 


\section{Referências bibliográficas}

DEBRAY, R. Curso de midiologia geral. Petrópolis, RJ: Vozes, 1993. 417 p.

MAINGUENEAU, D. Cenografia epistolar e debate público. In: POSSENTI, S.; SOUZA-E-SILVA, M. C. (org.). Cenas da enunciação. São Paulo: Parábola Editorial, 2008b. p. 115-135.

MAINGUENEAU, D. Gênero do discurso e cena de enunciação. In: MAINGUENEAU, D. Discurso e análise do discurso. Trad. Sírio Possenti. São Paulo: Parábola Editorial, 2015. p. 117-130.

MAINGUENEAU, D. Mídium e discurso. In: MAINGUENEAU, D. Análise de textos de comunicação. 5 ed. Trad. Cecília P de Souza-e-Silva. São Paulo: Cortez Editora, 2008a. p. 71-83.

MAINGUENEAU, D. O quadro genérico. In: MAINGUENEAU, D. Discurso literário. São Paulo: Editora Contexto, 2006. p. 229-246.

MAINGUENEAU, D. Hipergênero, gênero e internet. In: MAINGUENEAU, D. Doze conceitos em Análise do Discurso. São Paulo: Parábola Editorial, 2010. p. 129-138.

MAINGUENEAU, D. Gênese dos discursos. Tradução de Sírio Possenti. São Paulo: Parábola Editorial, 2008c. 184 p.

PÊCHEUX, M. O discurso: estrutura e acontecimento. Tradução de Eni Orlandi. Campinas: Pontes, 1990.68p.

POSSENTI, Sírio. Os limites do discurso: ensaios sobre discurso e sujeito. São Paulo: Parábola Editorial, 2009. 213 p.

REZENDE, B. R. M. P. R. Polêmica discursiva e intertextualidade: em pauta o compartilhamento de notícias na rede social. In: PERcursos Linguísticos. V. 6. N. 13. Vitória: UFES, 2016/02 (Revista Eletrônica).

REZENDE, B. R. M. P. R. Hipergênero e sistema de hipergenericidade: análise do funcionamento discursivo do Facebook. Uberlândia: Universidade Federal de Uberlândia, 2017 (Dissertação de Mestrado).

SAUSSURE, F. Curso de Linguística Geral. 28 ed. BALLY, C.; SECHEHAYE, A. (org.). São Paulo: Cultrix, 2012. 312 p. 
ZATI, P. O funcionamento da comunidade discursiva construída em torno das fanfictions. Uberlândia: Universidade Federal de Uberlândia, 2016 (Dissertação de Mestrado). 